\title{
Thought and Repetition in Bergson and Deleuze
}

\author{
Jonathan Sholl K. U. Leuven
}

\begin{abstract}
This essay explores the relation between repetition and thought in Bergson and Deleuze. In Bergson, this relation is seen in the method of intuition by which thought is made to think in time and in the 'rhythms' at work in how intuition is a contact with time or life, urging conceptual precision. This framework is used to clarify Deleuze's thought without image as that contingent encounter with the persistent forces of life that demand the perseverance of thought. Far from stressing difference alone, both link the repetition in life to the unsettling persistence required to develop a truly new thought.

Keywords: repetition, life, intuition, thought without image, method, encounter, insistence

What thought lacks most of all is repetition. This is an odd statement as we are tirelessly subjected to the repetitive nature of modern societies in which progress is measured in terms of continual production, and also for the pejorative nature of repetition in a time when philosophers seek the production of the new, the different. In a word: creativity. However, is turning to the philosophies of Henri Bergson and Gilles Deleuze helpful in not merely describing the nature of modern life, but in critiquing the ideals that exhibit their power over us? In what sense do their philosophies help to clarify the odd nature of repetition?

Recently, Bergsonism has been described as a "philosophy of difference, ${ }^{1}$ insofar as life is conceived as the production of differences and philosophy as a method for clarifying these differences, of which
\end{abstract}

Deleuze Studies 6.4 (2012): 544-563

DOI: 10.3366/dls.2012.0082

(C) Edinburgh University Press

www.eupjournals.com/dls 
we can see various examples throughout his work: difference in degree and kind, duration and space, quality and quantity, memory and matter, instinct and intelligence, dynamic and static religion, and so on. With Deleuze, this description is also applied to his rather complex empiricism that seeks to go beyond philosophies of subjectivity or representation so as to think difference in itself. Neither philosophy, however, is free of problems. Bergson's intuitive philosophy comes with the heavy baggage of anti-intellectualism (J. Russell 1912; B. Russell 1912: 347), romanticism (Lyotard 1991: 44-5) and a form of spiritual inspiration (Merleau-Ponty 1988). ${ }^{2}$ How could this approach actually provide philosophy with the needed tools to criticise modern ideals if thought is reduced to an irrational instinct? Does Deleuze's empiricism fare any better? This, too, comes with the baggage that if thought and life are characterised by the production and repetition of differences then this can easily lead to the dissolution of individual identity into a pure flux (Braidotti 1994: 117-23) or a nihilistic position that accepts chaos as inherent to life. A recent scholar of Deleuze, Keith Ansell-Pearson, formulates the problem as follows:

The problem of nihilism is not overcome in Deleuze's thinking but its difficulty and complexity are staged as such. The critical question, however, concerns whether the attempt to read univocal Being in terms of the primary play of difference and repetition amounts to a coherent philosophy of difference or results in a mode of thinking that exists only as in thrall to the new and the monstrous... In short, the question to be posed concerns whether Deleuze has produced a fetish of repetition... [Deleuze's linking of repetition to the eternal return] has little to say on the character of change, destruction, revolution and repetition, except that there be such phenomena. (Ansell-Pearson 1999: 82-3)

This crucial passage suggests that if the philosophy of difference advocates nothing more than the continual reproduction of novelty - stating that change occurs but not addressing how it occurs-then it would seem to be of little help for understanding how and why to do anything in the world. We seem to be left, then, with two impotent approaches for using a philosophical conception of difference to challenge modern ideals: Bergson leads us into a form of spiritual asceticism, Deleuze into a nihilistic 'fetish of repetition'. However, such problems are inherent to the label 'philosophy of difference' and mask how Bergson's intuition and Deleuze's thought without image are two ways for diagnosing the pathologies of thought, neither of which can be properly understood without an appeal to repetition. 
Both philosophers provide examples of the relation between thought and repetition that can be shown in the following ways. The first requires an examination of what philosophical intuition entails, not in terms of the chronological movements of thought that Bergson himself explored, but of the various intimations that he gave regarding the nature of an intuitive philosophy. The aim, then, will be to describe intuition as the methodical effort of thought to think in time, to be in a problem, entailing the precise cultivation of concepts. For Bergson, intuition is not merely the experience of difference (Carr 1914: 38) or the 'joy of difference' (Deleuze 2004: 33), but allows us to understand the élan vital in terms of a repetition without a telos. ${ }^{3}$ In other words, as Bergson showed that duration can be said of living beings and reality as such -all things or beings having their own rhythm or duration ${ }^{4}$ - the methodology of intuition could give us an insight into the nature of the élan vital as that insistent force behind life's evolution.

After laying this groundwork for which to better understand Bergson, the ontological implications of this approach will be explored by bringing this groundwork into dialogue with Deleuze's philosophy of repetition, in terms of what I call the 'rhythms of intuition' and the 'logic of repetition'. This will allow us to clarify the demanding relation between thought and repetition. As Deleuze takes up Bergson's insights via his 'thought without image' another link between thought and repetition can be demonstrated. If repetition is defined as an unrelenting force or pulsion that does not want to give itself up, the insistence or 'power' of difference, ${ }^{5}$ then our task is to understand repetition without reducing it to questions of progress, realisation or teleology, and thereby addressing the problem of the fetish of repetition. While repetition is a problematic and seemingly pejorative term in vitalistic philosophies, the success of this suggestion will have to be determined after a close examination of some key passages in Bergson and Deleuze and a creative rendering of what appears on the surface to lack creativity.

\section{Intuition as Cultivation: Having Done with Method?}

What would it mean, then, to have an intuitive philosophy? There are two primary points to be made: first, intuition ${ }^{6}$ entails a redirection of thought away from space and, second, it means to think in time. Regarding the first point, against the view of time that assumes it is given as a spatialised, static whole, intuition presupposes that change itself is essential, with no need of an underlying substance: 'There are changes, but there are underneath the change no things which change: change has 
no need of a support' (Bergson 2007: 122; original emphasis). Instead of looking for something immobile that is said to change, intuition enters into change by accepting the unforeseen and the irreversibility of time. This can be clarified by saying that the tendency of the intellect is to analyse what already exists (past-directed), whereas intuition implies creation, protesting time's spatialisation (future-directed). The problem is developing a concept adequate to this movement, since to do so requires going against the natural bent of our mind, which tends towards mechanism and finalism.

In Creative Evolution, the mechanistic model takes on the form of the cinematographical image in which the process of evolution is broken down into discrete parts that are then pieced back together, like snapshots were used to make a film, thus giving the appearance of movement. This image, however, tends towards a 'perpetual recommencement' (Bergson 1998: 306-7) -division ad infinitum-precisely because it spatialises time and thereby prevents adequate conceptualisation of movement itself. According to the finalistic position, on the other hand, beyond that which changes, that is, the faulty world of perception, there is something eternal that serves as the cause and sufficient reason for change, providing an external measure for what is changing. This beyond usually takes the form of a single concept from which all others can be deduced: be it Substance, Ego, Idea or Will (Bergson 2007: 18-19). However, in positing an eternal concept or substance in order to account for change this view presupposes a spatialised time that is a homogenised, static whole. Instead of an immobile snapshot of movement or evolution we get an immobile concept guiding movement from above: 'If movement is not everything, it is nothing; and if to begin with we have supposed that immobility can be a reality, movement will slip through our fingers when we think we have it' (Bergson 2007: 121). This is the problem of intuition: change is imperceptible not because it is beyond reality, but because it is reality, yet it is essential if we are to understand reality. If we are to think in time we have to make thought itself move.

This leads to the second point. Intuition is distinguished from intelligence as intuition entails thinking in time, not reflecting upon it: 'to think intuitively is to think in duration. Intelligence starts ordinarily from the immobile, and reconstructs movement as best it can with immobilities in juxtaposition. Intuition starts from movement, posits it, or rather perceives it as reality itself, and sees in immobility only an abstract moment, a snapshot taken by our mind of a mobility' (Bergson 2007: 22). To perceive movement, here, does not mean the visual act 
of seeing something with one's eyes since normal human perception cuts up reality by selecting: we focus on this and not that. The type of perception he suggests, then, is a deeper use of the mind, as when we follow the movement of a melody. The melody is pure change with nothing underlying it, each note bleeding into the next while remaining qualitatively distinct. As soon as we try to focus on each note, we lose the movement of the melody. It is intuition that allows us to make the division $^{8}$ between this qualitative movement and its quantification. The difficulty is that as soon as we try to fix upon this movement, it slips away, 'for it [the impulsion that set thought in motion] was not a thing but an urge to movement' (169). Intuition, then, is only successful if it is possible to grasp this movement itself, thereby making use of it so as to see duration in all things. ${ }^{9}$ This does not mean that intuition is duration, but that intuition is the means by which we can think in terms of duration.

A problem arises from this methodological suggestion. Does this view of thought lead to a form of anti-intellectualist romanticism such that thought is moved by a direct or divine vision leading it to sympathise with the flow or evolution of life itself? Can we circumvent such accusations that continue to haunt Bergsonism by clarifying the relation between intuition and method, in the sense that intuition is a process of cultivating thought?

The supposed romanticism of Bergson could be found on a few levels in his work, but it has been said that it is to be found above all in the fact that his entire philosophy is an effort to provide an aesthetic substitute for a lost religion and an emotionally unacceptable science' (Shklar 1958: 636). ${ }^{10}$ The aesthetic substitute suggests the image he constantly uses: the artist creating the unforeseen. The science without emotion would be remedied through his appeal to this more intuitive philosophy, one which refuses to reduce life to dead matter. Bergson himself goes so far as to claim that in philosophy one does not obey or command nature, but 'seeks to be at one with nature' (Bergson 2007: 104). ${ }^{11}$ What would this 'being at one with nature' entail? Does it mean that one finds a reason for existing or a natural place in the evolution of life or that nature finds its end and satisfaction in the human?

In Bergson there is a fine line between putting oneself into the movement of life, into life's creative evolution, and that of finding one's natural place or life's purpose. As in artistic creation, evolution is not the realisation of a plan or goal: it is neither harmonisation nor integration, but a necessary discord inherent to creation as it leaves harmony behind (Bergson 1998: 103, 117). Looking to art, then, is to look towards a field 
that acknowledges the role of the unforeseen in creation, not to appeal to a vapid holistic feeling. In this sense, the claim that intuition entails a romantic view of harmonising with nature is unwarranted. To have an intuition is to realise that one is part of a movement of life that has no end or goal, even if the human seems to be the only being capable of continuing this movement in his becoming conscious of it. ${ }^{12}$ Bergson thus defies this romantic tendency on two accounts: first, neither living nor thinking entails fitting into what already exists; second, as evolution is a matter of division, divergence and dissociation, the individual is not ultimately synthesised with this movement, but by entering into it by means of an adequate conceptualisation of it, the individual can engender further divergences. The point is not submission but creation, and this creation involves a method.

If thinking in time implies making use of duration, then we can see why Deleuze links Bergsonian intuition with method: 'Intuition is neither a feeling, an inspiration, nor a disorderly sympathy, but a fully developed method, one of the most fully developed methods in philosophy. It has its strict rules, constituting that which Bergson calls "precision" in philosophy' (Deleuze 1988: 13). While Deleuze's definition of intuition rightly suggests the demanding nature of philosophy, one which I will explore in the next section, intuition's relation to method needs clarification. Camille Riquier has recently argued that intuition and method should not be conflated, as Deleuze suggests, but that they are separate moments: at times, intuition precedes the development of a method, which happened in Bergson's early work, where the concept of intuition was still unformulated, as well as in a few privileged minds throughout history who acted without a plan (quand l'intuition manque de méthode); while at other times method precedes intuition, in the sense of the later Bergson writing so as to help those who are poor in spirit arrive at intuition (quand la méthode manque d'intuition) (Riquier 2009: 131-57). ${ }^{13}$ Riquier's distinction, while interesting, does not clarify the important issues at play: (1) if intuition initially lacks a method this means that it obtains its force from a contingent encounter and (2) the use of method to have an intuition means that thought requires continual effort so as to sustain the intuition that continually eludes it. Bergson's method does not entail a ready-made system that thought is guided by or seeks, but implies that intuition proceeds methodically, as a process of cultivating an idea. Intuition thus defies what is commonly accepted and yet demands the patience to develop this defiance into a positive thought. ${ }^{14}$ 


\section{The Rhythms of Intuition and the Logic of Repetition}

How, then, could intuition be put to work? I will try to answer this by clarifying the ontological implications of the methods found in Bergson while juxtaposing them with some insights by Deleuze: in Bergson the rhythmic nature of intuition points to the nature of the élan vital and in Deleuze repetition is implicated in the logic of a 'thought without image'. ${ }^{15}$ To clarify these complex relations, I define repetition as an insistent movement that thought is forced into, and its logic is the peculiar consistency that this repetition engenders. It is in contact with repetition that thought is produced, thereby requiring that thought is given a method so as to grasp that which moves it. It should be noted that while the following rhythms/degrees are ordered and in some ways cumulative, their sequential presentation is not to suggest that this is the order in which thought proceeds, but to merely show a way of approaching the methodical nature of thought in both philosophers.

\section{Bergsonian Rhythms}

First rhythm: the contact of intuition. For Bergson, merely having thoughts does not imply that one is thinking, nor does thought necessarily begin by formulating truths. Instead, thought has to be engendered: we have to be forced to think via a contingent encounter or contact with a force ${ }^{16}$ that creates novelty. For Bergson, what moves thought is 'not so much a vision as a contact: this contact has furnished an impulse, this impulse a movement' (Bergson 2007: 91). 'Philosophical intuition is this contact, philosophy is this impetus' (103). ${ }^{17}$ Intuition is not to have a clear idea or image guiding you, but is a contact with an imperceptible force, 'confused perhaps but decisive' (90). In this sense, philosophy does not find its origin in thought, in terms of reflection or representation, but in terms of the utilisation of a contingent encounter, being forced to create a problem peculiar to that which is moving you. ${ }^{18}$ Intuition opens thought unto a vital repetition, a movement that does not want to give itself up, and if we are to develop a concept adequate to this movement, without relapsing into our natural tendency to spatialise or generalise, then the violence of precision and method become crucial.

Second rhythm: the violence of intuition. To grasp the moving nature of reality and break with old forms of thought, the mind 'must do itself violence, reverse the direction of the operation by which it ordinarily thinks, continually upsetting its categories, or rather, recasting them' (Bergson 2007: 160). ${ }^{19}$ We are forced to recast ideas due to the shock 
of finding this movement at work within us and we cannot resort to ready-made ideas found all too easily in the sedimentation of a socialised common sense. ${ }^{20}$ Violence is needed to ward off the reproduction of clichés: applying what is old to the new. In order for this intuition to survive, then, we 'will be driven to strain the words, to do violence to speech' (Bergson 1977: 254) and thus to our very nature. This violence is also directed against representation, a natural tendency of thought. Here representation takes the form of the individual who is quick to pass judgement and to criticise an idea that does not fit into what is commonly accepted or 'reasonable' (Bergson 2007: 66). Representational thought resorts to vague generalities, trying to stretch pre-given concepts so as to account for more and more of reality. Intuition, on all accounts, protests against this tendency to generalise (the equal treatment of unequals) as this will only serve the practical, utilitarian needs of the intellect (which have their own domain).

Behind this violent protest against what Bergson calls the 'socialization of the truth' (Bergson 2007: 69) is a search for philosophical precision: 'What philosophy has lacked most of all is precision. Philosophical systems are not cut to the measure of the reality in which we live; they are too wide for reality' (1). The precision Bergson has in mind here comes from Plato's example of the good cook who cuts reality according to its natural articulations; however, in being precise we cannot appeal to an external measure or Platonic essence as a guide for how to shape concepts, but only to the object itself. In this sense, precision is a matter of conceptual simplification.

Third rhythm: thought as an effort without end. This precision, however, goes beyond conceptual tailoring to the intensification of one's life when intuition is linked with the necessity of a force that ' $\mathrm{had}$ to express itself' (Bergson 1977: 46). In other words, we are forced to think precisely because the élan vital is a 'creative exigency' (47): a recalcitrant repetition that intuition brings us into contact with. This intensification of intuition first occurs when we come into contact with this repetition; for example, upon looking into our own mind we glimpse the movement of duration within us. There is a further intensification when we go beyond ourselves into the evolution of life itself, ${ }^{21}$ realising that this movement is not solely within, but is at work in all living beings. Intuition, then, is not thought reacting upon something, but is that by which one enters into a repetitive activity that does not want to give itself up and demands conceptual precision so as to render that repetition living. Thus, precision is not only conceptual tailoring, but is a process of intensification of one's own life. As this encounter could be 
overwhelming due to the effort required to sustain it, intuition demands that the philosopher take risks.

But the philosopher runs these risks only because he has insured himself and because there are things of which he feels himself unshakeably certain. $\mathrm{He}$ will make us certain in our turn to the extent that he is able to communicate to us the intuition from whence he draws his strength. (Bergson 2007: 102) ${ }^{22}$

Here we are reminded that to have an intuition is not simply the ability to have a random thought or opinion about everything. Instead, it is a matter of knowing what one wants to do (feeling unshakeably certain), but without knowing how to get there (taking a risk). The contingency of the encounter produces a sense of certainty and what prevents us from lapsing into generalities is the fact that we do not know where the intuition will lead us. The utilisation of this encounter requires effort and perseverance to make it precise: in order to tailor one's singular idea, intuition has to be 'methodically cultivated and developed' (Bergson 2007: 62). It is only in the activity of creating a problem that one discovers what is to be developed.

To put this differently, intuition is that which vitalises the intellect, pushing it to form precise concepts. Images are evoked in order to express the intuition, but the intuition itself is without image. It knows not where it is going and has no image guiding it, but it acts with a force of necessity, an urgency seeking nothing more than its expression. It is a force that uses the intellect, it uses anything it can find-diverse images, if necessary. To think intuitively is not to be driven towards a final solution, but to be driven by a repetitive force that seeks expression: to be driven by life itself.

These rhythms demonstrate how the nature of intuition clarifies the nature of life itself in that Bergson's valuing of effort above all things not only pertains to the effort required to render an intuition precise, to fit its object, but also is an expression of his vitalism as he also finds the evolution of life to be characterised by a continual effort, that effort being the élan vital (Bergson 1998: 87, 127). He describes this effort, this impetus, as a tendency to act upon inert matter, but in such a way that there is no predetermined path for it to follow and thus it cannot be described in terms of finality: ${ }^{23}$ evolution has no model for creating forms. The effort of the élan vital, then, is purely contingent, not meaning that merely anything can happen but that it entails selection: it entails that the fortuitous encounter with matter is utilised such that a new life form is created out of the encounter ${ }^{24}$ or else the form is aborted and life hits a dead end. This is the risk that the 
élan vital takes as it encounters matter, and if it did not persevere, if it was not this peculiar form of repetition, there would be no evolution, no creation. Thus, in order to understand Bergson one has to separate repetition in thought and in life from teleology. We have to see that thought proceeds without an image just as life's evolution is an effort without end, in both the continual persistence of the élan vital and its unpredictable creativity. Evolution is the development of tendencies, not laws. Ultimately, intuition opens us to the metaphysical framework for understanding both the nature of thought and what reality itself must be like in order that we can know it: ${ }^{25}$ intuition is a thought without image and reveals to us the evolution of life without a telos.

\section{Deleuzian Logic}

First degree: contingency engenders necessity in thought. For Deleuze, as in Bergson, what forces thought is precisely a contingent encounter or contact with something in the world. While this contact could be various things-strong or frightening ideas, pleasing or traumatic experiences, Socrates, or even truth - this does not mean that thought is organised by such experiences as if by a first cause. Instead, the contact engenders the shocking or dizzying realisation that what is driving thought, using this contact to organise itself, is an ongoing force that is imperceptible, yet sensible; that is, it cannot be recognised or placed within a harmonious view of the faculties, shattering our previous conceptual framework, yet it is still felt. Thought entails the intense feeling of shock since it arises without knowledge of whence it comes:

Thought is primarily trespass and violence, the enemy, and nothing presupposes philosophy: everything begins with misosophy. Do not count upon thought to ensure the relative necessity of what it thinks. Rather, count upon the contingency of an encounter with that which forces thought to raise up and educate the absolute necessity of an act of thought or a passion to think. (Deleuze 1994: 139)

One does not create concepts for the pleasure of thought, but due to a necessity to express that which would otherwise be suffocating. Misosophy implies first that thought has us, we do not have it, ${ }^{26}$ and we create so as to be free of it. We simply do not know what contingency will create thought. Second, this encounter repeatedly obsesses us, forcing a problem to be posed that only pertains to this encounter. Like water when raised to a certain temperature can do nothing else than change phases, thought is forced to create due to the intensification that 
occurs from its encounter. As Badiou puts it: 'we think under pressure' (Badiou 2009: 116).

Second degree: the isolation of repetition. Through this encounter thought's activity isolates the thinker by violently denying generalities, the vagaries of common sense and good sense, not because thought detaches itself from life, but because it requires the passion and conviction to develop a concept, an Idea, that adequately expresses one's vital peculiarity. Reminiscent of Bergson, Deleuze directs this violence against representation, here taking the form of 'we know everything' or 'no one can deny...' (Deleuze 1994: 130). Because thought naturally takes the form of such universals, it is difficult to give up the ideas that one finds ready at hand: thought does not want to do violence to its own nature as this would apparently separate the individual from its own common sense, from society and from seemingly all that it values.

In other words, as thought is the contact with something which forces one to think, with an intense repetition that refuses universalisation, it requires that an individual deny socialised presuppositions. Highlighting this degree shows how not only Nietzsche but more profoundly Bergson inspired the way Deleuze links the disobedience of philosophical thought to effective repetition:

it is a question of someone-if only one-with the necessary modesty not managing to know what everybody knows, and modestly denying what everybody is supposed to recognize. Someone who neither allows himself to be represented nor wishes to represent anything. Not an individual endowed with good will and a natural capacity for thought, but an individual full of ill will who does not manage to think, either naturally or conceptually. Only such an individual is without presuppositions. Only such an individual effectively begins and effectively repeats. (Deleuze 1994: 130; my emphasis)

Within this quote we find some of the postulates of the dogmatic image of thought that Deleuze feels haunt philosophy: representation, good sense and common sense, identification, the subsumption of the singular under the universal, and the purely negative views of repetition. If one is to deny what 'everybody knows', to refuse the limitations of identity, one has to resist the given presuppositions of thought, but this can only be done by exploring another form of repetition that is neither redundancy nor generalisation but is an unrelenting force. For the philosopher, then, the issue is developing a concept that adequately captures that which moves thought, so as not to limit this movement or its ability to intensify you as a thinker. If this concept of repetition is linked to a 'thought without image', it demands a thought without end. In other words, 
thought is neither a matter of realising a goal, nor does its expression seek an end, such as identification. To think, one has to be persistent.

Third degree: repetition as perseverance and resistance. As the contingent and violent encounter produces a sense of urgency in thought, this urgency must be maintained in spite of the fact that we do not know where the thought will lead us. However, while anyone can abstractly have an idea, this idea has to be utilised: it has to be pursued with 'guile, perseverance and prudence ${ }^{27}$ if it is to have vitality. Ultimately, thinking requires taking a chance, throwing the dice, and allowing this chance to affect you without escaping you. As thought is continually shrouded in clichés when we start, the point being to get out of them by creating a precise idea that resists common sense, ${ }^{28}$ how are we to utilise an idea, to put an intuition to work, to achieve an effective repetition?

'True repetition', Deleuze writes in The Logic of Sense, 'appears as a singular behaviour that we display in relation to that which cannot be exchanged, replaced, or substituted' and as such 'addresses something singular, unchangeable, and different, without "identity" (Deleuze 1990: 328). As this true repetition 'authenticates the different', Deleuze uniquely links difference to repetition: 'Difference gives things to be seen and multiplies bodies; but it is repetition which offers things to be spoken, authenticates the multiple, and makes of it a spiritual event' (329). That true repetition is never of the Same, but of the Different, means not that to repeat is to enter into a pure flux where thoughts or identities dissolve into a sea of change, but it is to conceptualise a difference that insists in its vital singularity or virtual intensity and thus cannot be given an identity in terms of what already exists. Instead, to think difference is to think the conditions that allow a thing to determine its own identity via its repetition for itself. It is for this reason that every 'repetition is a transgression' (Deleuze 1994: 3) since to repeat is not to reproduce what already existed but to create the unforeseen. The individual effectively repeats by creating concepts according to that which is moving him or her.

How are we to understand this odd logic linking that which is unchangeable with that which is without 'identity', that is, difference? What does it mean to define true repetition as the insistence of difference? For Deleuze, repetition 'expresses a power peculiar to the existent, a stubbornness of the existent in intuition, which resists every specification by concepts no matter how far this is taken' (Deleuze 1994: 13f; my emphasis). A thinker who effectively repeats expresses a force that does not want to give itself up, one that stubbornly resists, and thus one that continually transgresses laws, the confines of representation, the 
marketing of opinions, and common sense. That ideas insist in their own intensity and vitality, and not in relation to transcendent or moral ideals, constitutes what could be called the 'nervous optimism'29 of thought's repetition. If thought is pursued with 'guile and perseverance' it will touch on those forces (be they evolution, the élan, temporality, difference in itself) which do nothing but resist all attempts to stifle them. To think without image is to create such that life and time do not suffocate within you, such that differences do not lack repetition, thereby allowing for ideas to resist the dogmatic images of thought.

The point of developing these degrees of thought in Deleuze is to show his indebtedness to Bergsonian intuition, not in the sense that Deleuze merely reproduces this concept, but in the sense that for Deleuze, too, thought is methodical, requiring effort. Similarly to how Bergson's intuition sheds light on the nature of the élan, Deleuze's thought without image is that whereby he can adequately conceptualise repetition as that intensive behaviour that authenticates difference. Thought arises out of a contingent encounter, forcing itself upon the individual and requiring the individual's separation from all presuppositions, be they from common sense or good sense, so as to grasp what is novel about this thought. The development of this thought in turn requires perseverance: it requires repetition. Thus, similarly to how the conceptualisation of movement required that thought itself was set in motion, this conceptualisation of repetition requires that thought itself must repeat. Thought is an expression without end, aim or finality since that which sets thought in motion is the insistence of difference, a repetition without a telos.

\section{Repetition and the Demands of Thought}

Does this foray into these levels of thought provide us with any insights concerning the diagnosis that began this essay, thought's lack of repetition? Bergson's intuition diagnoses repetition without difference in terms of spatialised time or the inert, immobile image of life subordinated to transcendent ends. Deleuze's thought without image diagnoses difference without repetition in terms of the natural images of thought that fail to grasp the insistence of difference. Two consequences emerge from these positions. First, thought is what opens us to a movement that refuses to relinquish itself, forcing thought to pose problems. This movement is pure activity and if we are to think actively, we must do violence to our natural tendency to stop this movement. Second, in order for thought to continue this movement, it must itself be obstinate, passionate: thought implies repetition. 
It remains for me to address the central problem that began this essay, the fetish of repetition, which my analysis seems to have exacerbated. This problem divides into two further issues, the first being that of conflating Bergson and Deleuze regarding the relation between difference and repetition and the second being that of Deleuze's emphasis on difference or creativity as production for its own sake.

As John Mullarkey rightly points out, Deleuze's views on repetition seem to place him squarely within a more Heraclitean view of pure flux, with true repetition being a productive or creative repetition, whereas Bergson would not give precedence to a pure mobility since a philosophy of change allows for both movement and stasis (Mullarkey 1999: 205-7). I hope not to have obscured this distinction, but instead I would like to claim that while this reading of Deleuze as a promoter of pure flux (philosopher of difference) is possible, this occludes the fact that repetition is not merely production, but is also that obstinacy or effort whereby difference is authenticated. The view of Deleuze as one who fetishises repetition assumes that repetition is nothing more than difference, and thus underemphasises the roles of perseverance, precision and resistance (the insistence of difference) for understanding both the nature of reality and the development of concepts. This view also masks how Bergson's views on effort and Deleuze's concept of repetition converge. ${ }^{30}$ While difference is accentuated in Deleuze, it cannot be thought without repetition. Insofar as intuition is understood as an effort to develop precise concepts that pertain to the movement of life or duration within all things, and insofar as repetition is captured in a thought without image as the insistence or perseverance of life in thought, we can understand Deleuze's claim of a 'profound complicity between nature and mind' (Deleuze 1994: 165). ${ }^{31}$ The effort of intuition, as with the thinker who effectively repeats, pertains to a form of resistance, a refusal to let a thought go unexpressed, and this resistance is effective as it adequately grasps the movement of life or nature that has engendered it.

This leads to the second issue, that of production for its own sake. Thomas Osborne problematises some recent appeals to creativity as that which ought to guide philosophy, particularly within the vitalist tradition from Bergson to Deleuze. ${ }^{32}$ Osborne points out that such a normative emphasis on creativity is part of a wider cultural assemblage, namely 'the creativity industries, consumerist individualism, the cult of the new as ever-changing fashion, the forces of intellectual and cultural productivism for its own sake, the performativity of "ideas" and culture' (Osborne 2003: 522). Osborne's prescription to this diagnosis 
of overproduction is to advocate inventiveness, rather than creativity, since the former concept appeals to the inertia of thought and to hard work: 'Work involves repetition. Not repetition of the same object or specific theme necessarily, but repetition of the same activity, repetition in the name not just of seeking an answer to something but of locating, deepening, embellishing a problem' (520). Thus, instead of the focus on creativity as the heroic or romantic production of something new, he pleads for an acceptance of inertia and for the obsession with a problem such that one does not seek closure, but the opening of further possibilities.

This problematic converges precisely with the above explication in that my attempt to de-emphasise the role of difference in Deleuze's work was done by giving proper weight to repetition as the unrelenting forces of life acting upon us and as the obstinacy required for thinking these forces. If one stops their thinking activity with creation, then all we have is difference without repetition: a true fetish of repetition (which is quite rampant within modern consumerist societies). Is it the case, however, that this inertia of inventiveness is a form of repetition without difference? I think it is not, since it is precisely in the process of repeating an activity that difference, individuality or novelty is made possible or authenticated. To continually repeat an attempt is to refuse mindless change and by not giving up thought is intensified, ensuring that novelty is possible. As Osborne wants to remove creativity from its seemingly normative status, I would like to take difference off its pedestal by giving more emphasis to these underappreciated qualities of repetition.

The logic of repetition behind Deleuze's thought without image thus suggests that philosophical thought is not the random production of novelties, a seeming 'fetish of repetition', but is a violently intense and sustained battle of the individual 'full of ill will' with clichés, opinions and the marketing of ideas, and the refusal to give up this battle. In What is Philosophy? Deleuze and Guattari go so far as to conclude that the 'concept has a power of repetition', in the sense that it is 'virtual', 'incorporeal' and 'impassible' (Deleuze and Guattari 1994: 159). In other words, a concept does not exist, it insists. Thus, while it is novelty or difference that wakes thought from its stupor, it is repetition or persistence that gives thought its force, waking it from its torpor. Both Bergson and Deleuze take seriously the consequences of a blocked repetition, the inability to make differences move, and the failure to adequately conceptualise the movement of thought-all of which could be said to prevent the realisation that 'discipline is a vehicle of joy'. ${ }^{33}$ Thus, the repetition inherent to a thought without image and 
the insistence of the élan vital place demands on thought not merely to think differently or to be different (these are givens), but to persevere so as to make thought move, to effectively repeat. To have an intuition, to fight the given dogmatic image of thought, is to methodically cultivate resistance.

\section{Notes}

1. Cf. Deleuze 1988 and 2004; Ansell-Pearson 1999, 2002; Guerlac 2006; Mullarkey 1999.

2. In his essay In Praise of Philosophy, Maurice Merleau-Ponty rightly argues that intuition is not a 'prenatal inspiration' (1988: 19), but by describing thought in terms of 'incarnation' (27), life as 'primordial unity' (28), and creating 'out of nothing' (28), he reads too much Christian theology into Bergson's work and thus needlessly distorts it.

3. While the complex relation between memory and repetition as developed in Matter and Memory plays a crucial role in Deleuze's reading of Bergson, it will be largely put aside in order to make my argument. I do not feel that the argument is hindered by doing so since my concern is the relation between thought and life (the élan) as developed in Creative Evolution and The Creative Mind, rather than thought/repetition and memory.

4. While in Time and Free Will (1971) Bergson developed the concept of duration solely in terms of the immediate data of a personal consciousness, it was not until Matter and Memory that duration became pluralised and opened onto the rhythms and vibrations of all things and beings. See Bergson 1991: 204-9.

5. 'In every case, repetition is the power of difference and differenciation' (Deleuze 1994: 220). My definition of repetition, then, focuses on the third synthesis or repetition in Deleuze as that which combines the actual repetitions of habit and memory with the virtual repetition of intensities. This repetition is the process of relating intensities such that they are expressed in the actual. Repetition will thus be linked to the 'dice throw' of thought as not knowing what will happen but of allowing something to happen to us.

6. Camille Riquier, in Archéologie de Bergson: Temps et métaphysique (2009: 156), interestingly points out that Bergson initially used the English word 'feeling' to signify that which pertains to the immediate data of consciousness, as he was then unable to find a proper concept in French before eventually using 'l'intuition'.

7. Bergson would later come to view differential calculus as contributing to a proper understanding of time as movement.

8. 'Intuition as method is a method of division' (Deleuze 1988: 22).

9. 'Intuition is not duration itself. Intuition is rather the movement by which we emerge from our own duration, by which we make use of our own duration to affirm and immediately to recognize the existence of other durations, above and below us' (Deleuze 1988: 32-3; my emphasis).

10. Another reading of Bergson as one who has a romantic, teleological view of 'Life' can be found in Jean-François Lyotard's The Inhuman (1991: 44-5).

11. If understood as 'to sympathise with nature', however, the romantic overtones could be lessened. 
12. In saying 'seems' here I am more generous than needs be to Bergson. He does not seem to suggest that there could be another line of evolution that goes beyond the human; instead, he tries to find a way to extend the human beyond itself. Keith Ansell-Pearson takes this quite seriously and examines the claim that philosophy is a matter of going 'beyond the human condition' (1999: passim).

13. I disagree with Riquier's phenomenological reading of intuition, seemingly influenced by Heidegger or Jean-Luc Marion, his teacher. In describing intuition in terms of a weakness or obscurity patiently awaiting the reception of light and as a humility facing giants (David vs Goliath), he reduces intuition to yet another spiritual interpretation as in Merleau-Ponty 1988.

14. For more on the power of negation in intuition see Bergson 2007: 89-90, and for the common impatience of philosophy see Bergson 2007: 24.

15. By linking intuition and a thought without image I hope not to conflate Bergson and Deleuze, but to build on Alain Badiou's suggestion that Bergson plays a more central role in Deleuze's overall thinking than Spinoza or Nietzsche (Badiou 2000: 39). I attempt to clarify this suggestion by rethinking thought's relation to repetition. Moreover, since my concern is with the concepts of repetition and thought without image, I will focus mainly on Difference and Repetition as it is there that Deleuze develops these concepts.

16. I will be using the word 'force' in the coming pages to refer to the movement or quality that Bergson attributes to the élan as that which ensures change, evolution and so on. This force is that which, upon being experienced, propels one into thinking. For Bergson, it is by entering into this movement (be it temporality or evolution) that one is urged to think it, as if pushed by a force. To avoid the unhappy formulation that one is forced to think the force that forces thought, I will use 'force' interchangeably with other concepts such as movement or repetition.

17. Bergson also describes philosophy as 'a contact with the creative effort' (1998: 370). In Matter and Memory intuition is similarly described as a 'contact with the real' (1991: 185-6), the real being the undivided, lived continuity of duration.

18. Deleuze provides an interesting account of the nature of creating problems in his Bergsonism 1988: 13-35.

19. Ansell-Pearson argues that Deleuze's thinking 'retains the Bergsonian conviction that thought must assume a monstrous form and that the break with established forms of thought must be a violent one' (1999: 83).

20. 'Common sense, then, or as it might be called, social sense, is innate in normal man, like the faculty of speech, which also implies the existence of society and which is none the less prefigured in individual organisms' (Bergson 1977: 106).

21. This double intensification is described in The Two Sources of Morality and Religion (1977: 250). In Creative Evolution one can see how the effort of life that is passed on from one generation to the next, dividing as it moves along, is 'distributed amongst individuals without losing anything of its force, rather intensifying in proportion to its advance' (1998: 26; my emphasis).

22. For more on how an encounter can be lucky or unlucky see Bergson 1977: 229-30.

23. We can see many examples of this rejection of finalism: Bergson 2007: 13, 20, 52, 99; Bergson 1977: 52, 196-7. It should also be noted that Bergson does endorse a form of external finalism in Creative Evolution 1998: 41, 265-7. However, Deleuze rightly argues that we are to understand this in the sense that nature has different planes (no single route) and that each one has its own plan (showing the double meaning of the French word 'plan') or its own tendency 
that it develops (Deleuze 1988: 131, n.2). As Bergson writes: 'evolution does not mark out a solitary route, that it takes directions without aiming at ends, and that it remains inventive even in its adaptations' (Bergson 1998: 102; my emphasis).

24. 'Life is, more than anything else, a tendency to act on inert matter. The direction of this action is not predetermined; hence the unforeseeable variety of forms which life, in evolving, sows along its path. But this action always presents, to some extent, the character of contingency; it implies at least a rudiment of choice' (Bergson 1998: 96).

25. In this sense, Bergson's work resonates with Thomas Kuhn's depiction of scientific progress as the solving of problems through continued precision, not as the advancement towards some transcendent Truth; see Kuhn (1996: 170-3).

26. 'We are always patients where Ideas are concerned' (Deleuze 1994: 219).

27. Ansell-Pearson argues that thought in Deleuze is not a method as this 'implies a collaboration of the faculties that is far too harmonious and equilibrial, as well as too determined by social values and established norms of discipline'. Instead, thought involves a form of culture, being 'caught up in excessive repetitions of a compulsion to live beyond the old morality' (Ansell-Pearson 1999: 83). However, method need not mean that thought uses a ready-made system, but that in order to cultivate an idea, it proceeds methodically and painfully, with perseverance. See also James Williams (2003: 19) who provides an interesting account of the method of Deleuzian dialectics.

28. In the chapter entitled 'The Painting before Painting...' in Francis Bacon: The Logic of Sensation, Deleuze describes how painting is not merely making random marks, but involves the ability to utilise them, to create something out of them. A contingent choice has to be pursued, made precise, and this requires effort. 'One can fight against the cliché only with much guile, perseverance, and prudence: it is a task perpetually renewed with every painting, with every moment of every painting' (Deleuze 2003: 68). I feel that this analysis is profoundly inspired by Bergson's description of the continual effort required to develop and sustain philosophical intuition.

29. Here again I borrow a phrase from Deleuze's Francis Bacon where he claims that Bacon's vitalism could be defined as being 'cerebrally pessimistic, but nervously optimistic' (Deleuze 2003: 43).

30. The following passage from Matter and Memory suggests the relation between habitual repetition and difference: 'The progress which is brought about by repetition and practice consists merely in unfolding what was previously wrapped up, in bestowing one of the elementary movements that autonomy which ensures precision without, however, breaking up that solidarity with the others without which it would become useless. We are right when we say that habit is formed by the repetition of an effort; but what would be the use of repeating it, if the result were always to reproduce the same thing?' (Bergson 1991: 111).

31. We set aside here the further problem that can be raised within Deleuze's work of a possible panpsychism or injection of thought into being (Brassier 2008).

32. This becomes the main focus of Deleuze and Guattari's What is Philosophy? (1994) where philosophy is defined as the creation of concepts that resist the present. While it is usually the case that Deleuze and Guattari's texts are something different than Deleuze's own work, many of the essays contained in What is Philosophy? share much in common with Deleuze's early work.

33. This phrase is attributed to the musician Robert Fripp. 


\section{References}

Ansell-Pearson, Keith (1999) Germinal Life: The Difference and Repetition of Deleuze, London: Routledge.

Ansell-Pearson, Keith (2002) Philosophy and the Adventure of the Virtual: Bergson and the Time of Life, London: Routledge.

Badiou, Alain (2000) Deleuze: The Clamor of Being, trans. Louise Burchill, Minneapolis: University of Minnesota Press.

Badiou, Alain (2009) Pocket Pantheon: Figures of Postwar Philosophy, trans. David Macey, London: Verso.

Bergson, Henri (1971) Time and Free Will: An Essay on the Immediate Data of Consciousness, trans. F. L. Pogson, London: Redwood Press.

Bergson, Henri (1977) The Two Sources of Morality and Religion, trans. R. Ashley Audra and Cloudesley Brereton, Notre Dame, IN: University of Notre Dame Press.

Bergson, Henri (1991) Matter and Memory, trans. Nancy Margaret Paul and W. Scott Palmer, New York: Zone Books.

Bergson, Henri (1998) Creative Evolution, trans. Arthur Mitchell, Mineola, NY: Dover Publications.

Bergson, Henri (2007) The Creative Mind, trans. Mabelle L. Andison, Mineola, NY: Dover Publications.

Braidotti, Rosi (1994) Nomadic Subjects: Embodiment and Sexual Difference in Contemporary Feminist Theory, New York: Columbia University Press.

Brassier, Ray (2008) 'The Expression of Meaning in Deleuze's Ontological Proposition', Pli: The Warwick Journal of Philosophy, 19, pp. 1-36.

Carr, H. Wildon (1914) The Philosophy of Change: A Study of the Fundamental Principle of the Philosophy of Bergson, London: Macmillan.

Deleuze, Gilles (1988) Bergsonism, trans. Hugh Tomlinson and Barbara Habberjam, New York: Zone Books.

Deleuze, Gilles (1990) The Logic of Sense, trans. Mark Lester with Charles Stivale, London: Continuum.

Deleuze, Gilles (1994) Difference and Repetition, trans. Paul Patton, New York: Columbia University Press.

Deleuze, Gilles (2003) Francis Bacon: The Logic of Sensation, trans. Daniel W. Smith, London: Continuum.

Deleuze, Gilles (2004) 'Bergson's Conception of Difference', in D. Lapoujade (ed.), Desert Islands and Other Texts 1953-1974, trans. Michael Taormina, Los Angeles: Semiotext(e), pp. 32-51.

Deleuze, Gilles and Félix Guattari (1994) What is Philosophy ?, trans. Hugh Tomlinson and Graham Burchell, New York: Columbia University Press.

Guerlac, Suzanne (2006) Thinking in Time: An Introduction to Henri Bergson, Ithaca: Cornell University Press.

Kuhn, Thomas S. (1996) The Structure of Scientific Revolutions, 3rd edn, Chicago: University of Chicago Press.

Lyotard, Jean-François (1991) The Inhuman, trans. Geoffrey Bennington and Rachel Bowlby, Stanford: Stanford University Press.

Merleau-Ponty, Maurice (1988) In Praise of Philosophy and Other Essays, trans. John Wild, James Edie and JohnO’Neill, Evanston, IL: Northwestern University Press.

Mullarkey, John (1999) Bergson and Philosophy, Edinburgh: Edinburgh University Press.

Osborne, Thomas (2003) 'Against 'Creativity': A Philistine Rant', Economy and Society, 32:4, pp. 507-25. 
Riquier, Camille (2009) Archéologie de Bergson: Temps et métaphysique, Paris: Presses Universitaires de France.

Russell, Bertrand (1912) 'The Philosophy of Bergson', The Monist, 22:3, pp. 323-47. Russell, John E. (1912) 'Bergson's Anti-Intellectualism', The Journal of Philosophy, Psychology and Scientific Methods, 9:5, pp. 129-31.

Shklar, Judith (1958) 'Bergson and the Politics of Intuition', The Review of Politics, 20:4, pp. 634-56.

Williams, James (2003) Gilles Deleuze's Difference and Repetition: A Critical Introduction and Guide, Edinburgh: Edinburgh University Press. 